\title{
Primary Prevention of Heterotopic Ossifications After Total Hip Replacement: Electromyotomy Technique
}

\author{
Jan Debre*, Zdenek Stepan, Jiri Dupal, Jan Vanicek, Jan Potesil \\ Orthopaedic Department of Sumperk Hospital, Sumperk, Czech Republic \\ Email address: \\ jan.debre@nemocnicesumperk.cz (J. Debre) \\ ${ }^{*}$ Corresponding author \\ To cite this article: \\ Jan Debre, Zdenek Stepan, Jiri Dupal, Jan Vanicek, Jan Potesil. Primary Prevention of Heterotopic Ossifications After Total Hip Replacement: \\ Electromyotomy Technique. Journal of Surgery. Vol. 9, No. 5, 2021, pp. 238-245. doi: 10.11648/j.js.20210905.15
}

Received: August 1, 2021; Accepted: August 11, 2021; Published: October 19, 2021

\begin{abstract}
We compared the benefit of modification in surgical technique in relation to primary prophylaxis of heterotopic ossifications after total hip replacement with straight stem. This modification contains the so-called electromyotomy technique and was compared versus standard „,cold blade“ technique. Two groups were assessed and matched by BMI, sex, age and arthrosis type undergoing hip replacement. Traumatic, dysplastic and rheumatic hips were excluded. A total of 682 patients were evaluated, 262 cemented, 402 uncemented and 18 hybrid types with minimum of 1 year follow-up (average 5.6 years). The standard "sharp blade" technique contained 313 hips, the alternative contained 369 hips. Surgeries were performed according to the same protocols and by one team via anterolateral approach. Patients with risk factors for heterotopical ossifications and administration of secondary prophylaxis modalities were excluded. The development of heterotopic ossification were assessed with blind control of radiologic specialists (Brooker's grades). Heterotopic ossification (HO) developed in $32.69 \%$, totally in 223 patients. Of those clinically relevant (Brooker III and IV grades) were $8.94 \%$, in 61 patients. In standard group there were $137 \mathrm{HO}$ in 313 hips (43.76\%), clinically relevant in 12.78\%, 40 patients. In this group there were 123 cemented hips with $53 \mathrm{HO}, 174$ uncemented with $74 \mathrm{HO}$ and 16 hybrid prostheses with $10 \mathrm{HO}$. Average age was 68.53 years, 153 males, 160 females. In alternative electromyotomy group there were 369 hips with 86 HO (23.30\%), clinically relevant $\mathrm{HO}$ cases developed in 5.69\%, 21 patients. HO in particular types: 139 cemented hips with 43 HO, uncemented 228 with $42 \mathrm{HO}$ and hybrid 2 with $1 \mathrm{HO}$. Average age was 70.56y, males 171, females 198. Statistic values of HO occurence between these groups favourising the electromyotomy group were significant, such as comparing the particular Brooker grades distribution and prosthesis type (cemented, uncemented). Significant decrease was observed mainly in uncemented joint replacements and in clinically relevant grades in electromyotomy group. A novel perspective on primary prophylaxis of heterotopic hip ossification after straight femoral stem total hip replacement with engagement of modification in surgical technique so called electromyotomy is presented. Statistical analysis of results in ossification development significantly favorising modified technique in all types of prosthesis fixation, notably in uncemented prosthesis types. The main drop in counts of clinicaly relevant grades of osifications is also statistically relevant. According to these findings this surgical step is routinely implemented in our technique of straight stem implantations nowadays.
\end{abstract}

Keywords: Total Hip Replacement, Complications, Heterotopic Ossifications, Prophylaxis, Surgery Technique, Anterolateral Approach

\section{Introduction}

Heterotopic ossifications after implantation of total hip replacement are the well defined and stratified complication approved by the International Hip Society and are included in the $9^{\text {th }}$ revision of the International Classification of Diseases under the code ICD-9 728.13. Symptomatic heterotopic ossification occures mainly within 1 year after surgery with consequence of joint stiffness, reduction of range of motion and radiographic findings. The $3^{\text {rd }}$ and $4^{\text {th }}$ degree according to Brooker scale are defined as a complication after total hip replacement. This complication stratification is classified into group 3 (complications requiring unplanned surgical intervention, prolonged 
hospitalization or re-admission of the patient) and group 4 (complication associated with an event resulting in a threat to the limb or life requiring immediate invasive treatment) [7]

Heterotopic ossification (HO) is a process of formation and maturation of the trabecular bone in soft tissues where it's normally not present. Its development is well known after particular injuries, burns, CNS damage (brain, spinal cord) or in some genetic diseases $[5,17,22]$. It is formed by cartilage with subsequent enchondral ossification. Topographical regions of the $\mathrm{HO}$ are the intermuscular planes, the muscle attachements and joint ligaments. Configuration of the periosteum is not violated [1]. The exact cause and pathophysiological mechanisms why particulary these tissues are the site of ossification development is not definitelly explained nowadays.

Implantation of total hip replacement is a trauma for surronuding soft tissues and $\mathrm{HO}$ development is the reaction to this trauma. Three basic factors are needed for the formation and development of ossification: stimulus (to start the signal pathways), inducible potent osteoprogenitor cells and microenvironment suitable for osteogenesis [28]. Intensive proteomic research is carried out on specific triggers and the mechanism of its action in connection with bone metaplasia. The beginning of the ossification process is the fibroblastic metaplasia. A well-demarcated zone of fibroblastic proliferation can be distinguished, followed by chondroblasts and possible osteoblasts with newly set blood vessels and Harvesian canals [24]. There are several theories of the origin of progenitors producing heterotopic ossifications. The candidates are bone marrow stem cells [21], intersicial cells between the muscle fibers [28], fully differentiated endothelial cells [16], cells in circulation [26]. All of those could undergo a transition to the mesenchymal progenitor of osteoblasts [15]. Immune inflammatory processes are involved in massive cytokines mediated formation of extrasceletal heterotopic ossification [14]. Progenitor cells wear endothelial markers (Tie-2) and simultaneously express several neural markers. Subsequent production of peripheral neurotransmitters affects the formation of osteoblasts [22]. These cells from the endoneurium of the peripheral nerves are transferred to the vessels of the endoneurium and enter the circulation of newly formed vessels of heterotopic ossification, while undergoing partial osteogenic diferrenciation during transport [13]. In the subsequent 72 hours after the surgery, with the massive mitotic activity of these cells, a cellular basis is created for further formation, development and modification of ossification.

Electrocoagulation and electrotomy methods use the thermal effects of high-frequency electric currents. A large current density is formed on a handpiece electrode that has a tip or a narrow blade. When this electrode comes into contact with the tissue, the thermal effects are so great that water evaporates from the cells. High temperature results in coagulation of tissue and blood proteins, so the electrotomic incision does not bleed. The working frequency of electrotomy devices is $\sim 3 \mathrm{MHz}$, power adjustable $0-500 \mathrm{~W}$. The shape of the cutting electrode varies according to the purpose of usage. Electrotoms with a power of up to $50 \mathrm{~W}$ are used in ophthalmology and dentistry, devices with higher performance in abdominal surgery and traumatology. Electrocoagulation is carried out by the same apparatus with separate electrodes, the principle is to stop the bleeding vessel by coagulation of proteins at a high temperature [9]. Triggered changes in tissues depend on the voltage and intensity of the current, tissue resistance, frequency, anatomical localization of the lesion and its extent, length of application, shape of the active electrode, type of current. The non-modulated (continuous) provides clean and fine incision, minimal coagulation. The modulated (intermittent) provides pure coagulation, unsuitable for cutting. The mixed current could do both: cut and coagulation, but cut is wider than with pure electrotomy [11].

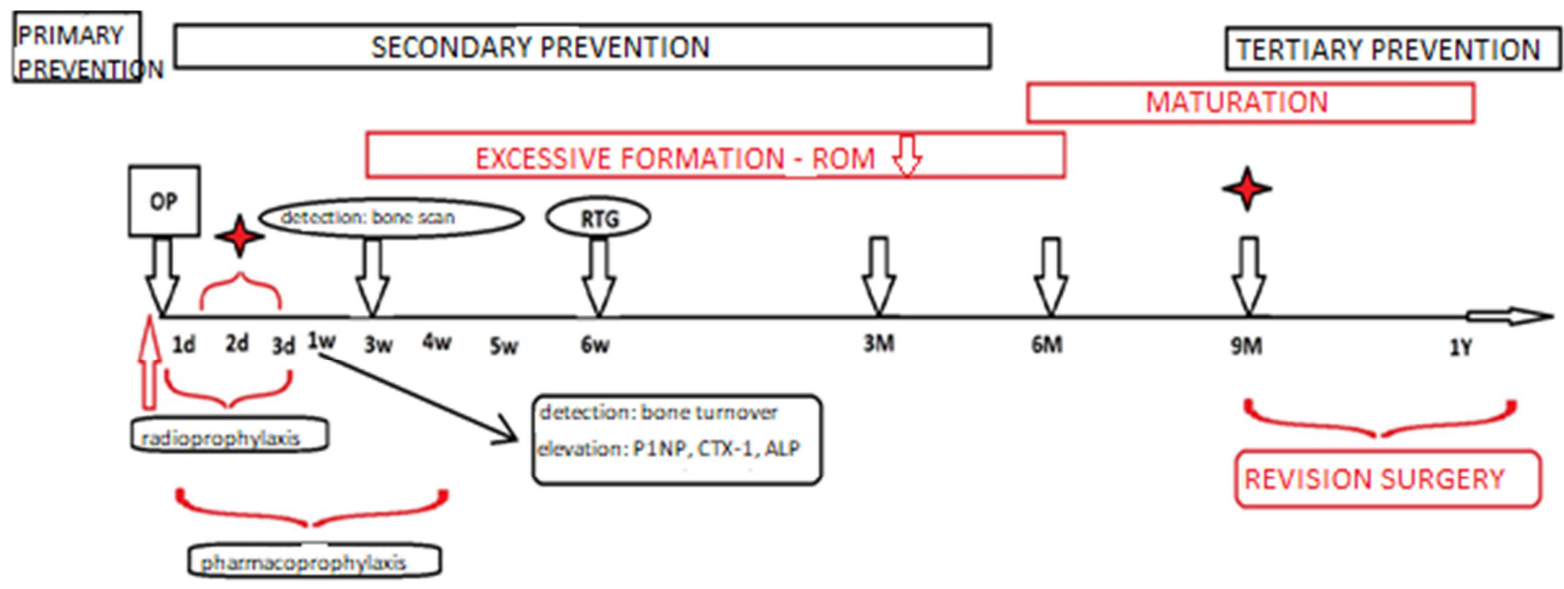

HETEROTOPIC OSSIFICATION

Figure 1. Time axis of heterotopic ossification development and possible modalities of its detection in daily practice. 
The majority of protection against heterotopic ossification is based on prevention at individual levels. Most of all, the primary prevention. This contributes intervention in changeable risk factors (in relation to the patient and in relation with the surgery) in order to reduce the risk of developing HO. Here we can influence the course of the surgery, its time, surgical approach, choice of endoprothesis, soft tissue manipulation, blood loss, drainage of possible dead anatomical spaces to prevent hematomas. And furhter to determine according to the known risks of the patient, who will be indicated for the secondary prevention. This consists of radioprophylaxis or pharmaco-prophylaxis [25, 27]. If ossification already takes place, there are only few modalities to prevent its development, maturation and formation with aim to reduce the degree so it remains clinically asymptomatic. This process remains hidden in a daily clinical practice as detection of ossification is not possible until inspection of radiograph six weeks after surgery. If a grade III or IV according to Brooker scale is already evident at this time and the clinical range of motion is affected, it is very likely that the patient will have a revision surgery. Since none of the methods is able to reverse the process in such a case, and the clinical correlation of the radiologic finding is present, the revision surgery is fully indicated after the maturation process. That is approximately after the $9^{\text {th }}$ month (better one year) after the implantation of the prosthesis [22]. Although earlier revisions are described in the literature, they are associated with a higher relapse of clinically significant degrees of ossification [6]. If at week six the radiologic picture is found intact, or if there are lower grade ossifications (Grade I and II), it is advisable to check the patient $3^{\text {rd }}, 6^{\text {th }}$ and $12^{\text {th }}$ month after surgery, according to protocol. If the $\mathrm{HO}$ is not present on $\mathrm{x}$-ray at one year after implantation, its later formation is possible, but unlikely. Time axis of development, maturation and possible detection of ossification process is drawn on Figure 1.

\section{Patients and Methods}

The aim of this study is to evaluate the effectiveness of primary prevention of heterotopic ossification after total hip replacement with straight stems by using modified surgical technique using electrotomy. Uniformity in proshtesis design regarding to the same approach for the femoral canal preparation we chose the straight stems (both cemented and uncemented types) in both groups of patients prospectively evaluated with minimum of 1 year follow-up (average 5, 6 years).

\subsection{Zero Hypothesis}

The zero hypothesis was stated: Electromyotomy technique in antero-lateral approach during implantation of total hip replacement with a straight femoral stem does not affect the frequency of development of total number and, most of all, clinically relevant (Brooker grade III and IV) heterotopic ossifications.

\subsection{Description of Surgical Technique}

Antero-lateral approach according to Watson - Jones was used, the groups vary according to the technique of detaching the muscle mass of gluteal muscles from a greater trochanter (blue line - Figure 2). This approach is commonly stated as risky for the emergence of heterotopic ossifications, mainly because the manipulation in abductor hip compartment [10]. In addition, when implanting a straight-stem endoprothesis (whether cemented or uncemented), it is necessary to cut the tendon attachments in the anterolateral border of the greater throchanter to access the entrance for the rasps and the final stem in femoral canal. The minimum of the $1-1.5 \mathrm{~cm}$ of the tendons (musculus gluteus medius et minimus) are left on greater trocahnter for later reconstrucion. For that we used the silon stitches. After the skin incision and opening of the fascia by a slightly oblique ventrally concaved cut is made and afterwards this release step takes place. If the tendons are not cut, the muscle fibres are definitelly torned by huge power with retractors during the approach to the femoal canal in the "figure of four position" and are afterwards very difficult to reconstruct. The red line on Figure 3 represents the correct positiong of the straight stem (prevention of varus or valgus malalignment) and corresponds to the inner layer of lateral cortex of the femoral bone.

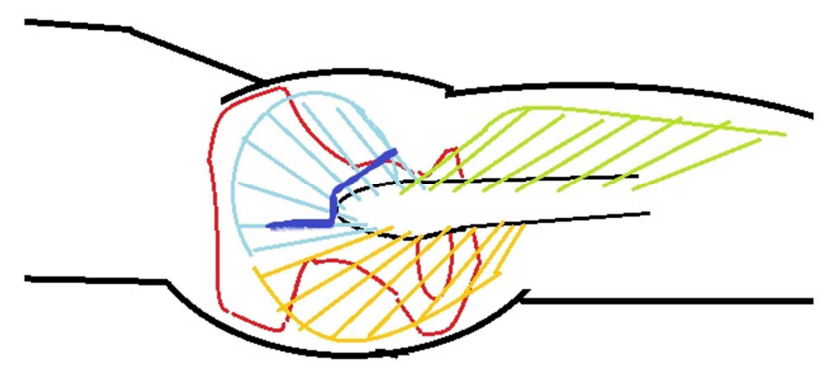

Figure 2. Particular surgical modified step: blue line represents the cut.

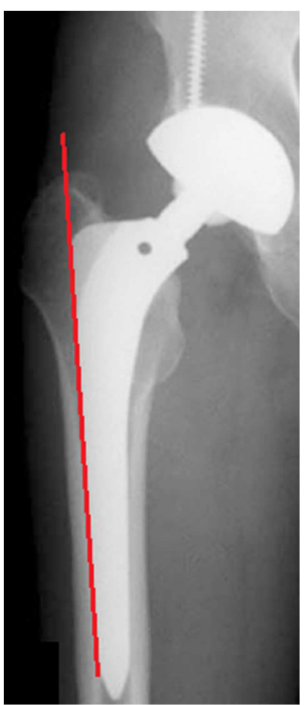

Figure 3. Correct positioning of the straight stem. 


\subsection{Patients and Implants}

Prospective longitudinal cohort study was designed to compare the two groups. These were assessed and matched by BMI, sex, age and arthrosis type undergoing hip replacement. Traumatic, dysplastic and rheumatic hips were excluded. Uncemented cups and straight stems with microporous titanium plasmapore surface with a high primary and secondary stability were implanted (ISOTANF TiAl6V4 titanium alloy - ISO 5832 - III). The cemented types had acetabular polyethylene components (ISO 5834 - I., sterillised in the nitrogen and with radiation of $25 \mathrm{kGy}$ ) and straight smooth surgical steel stems were both cemented with standard PMMA cement. A combination of both were the hybrid ones. The frictional coupling was ceramic heads (32 $\mathrm{mm}$ ) and ceramic inlays in uncemented types and polyethylen and metal heads $(32 \mathrm{~mm})$ in cemented variants. In the hybrid types there were polyethylene inlay in uncemented cup and straight cemented surgical steel stem with metal head $(32 \mathrm{~mm})$. Surgeries were performed in subarachnoideal blockage with epidural catheters for next 72 hours for pain control. Suction drains were routinelly administered for 24 hours after the surgery. Patients were mobilised next day after the surgery with full weight bearing.

Radiograms of the pelvis with both hip joints in two projections were revised by an independent physician at the interval of check-outs according to the protocol: preoperative, after the procedure, after 6 weeks, 3 months, 6 months and 12 months post surgery. The main information was wheter the ossification is or is not present (and what grade) on radiograph at 1 year follow up radiographic control. The findings were classified according to the Brooker scale. Scans that were not searchable meant that the patient was excluded from the study.

We analyzed the data using the STATISTICA 12 CZ 2017 statistical program. Fisher's accurate test (test on conformity/homogenity of variances of two independent selections) and Wilcoxon test (testing the hypothesis of equality of distribution functions based on verification of symmetrical distribution of the observed random quantity) were used. The value $<0.05$ was considered significant.

\section{Results}

From I/2015 to XII/2016 overall 682 hip replacements were evaluated, 262 cemented, 402 uncemented and 18 hybrid types with minimum of 1 year follow-up (average 5.6 years). Heterotopic ossification (HO) developed in 32.69\%, totally in 223 patients, which is consistent with published data from other authors [7].

The standard "sharp blade" group contained 313 hips and developed 137 ossifications (43.76\%), clinically relevant in $12.78 \%, 40$ patients. The particular Brooker grades were: I. 57, II. 40, III. 32 and IV. 8 patients, $41.60 \%$, 29.19\%, 23.35\% and $5.8 \%$ respectively (of total ossifications in this group). 123 hips were cemented, that is $39.29 \%$ of all hips in standard group. In cemented group developed $53 \mathrm{HO},(0: 70$,
I: 21, II: 15, III: 13, IV: 4). Uncemented were 174 hips, that is $55.59 \%$ of all hips in standard group and $74 \mathrm{HO}$ developed (0: 100, I: 39, II: 16, III: 15, IV: 4). 16 prostheses were hybrids with $10 \mathrm{HO}$ (0: 6, I: 2, II: 4, III: 3, IV: 1). Distribution in standard group were cemented implants $43.09 \%$, uncemented $55.59 \%$ and hybrids $5.11 \%$. Ossifications in this group were $43.08 \%$ of cemented implants, $42.52 \%$ of uncemented implants, $62.5 \%$ hybrid implants. Clinically relevant grades were $10,56 \%$ in cemented, $8.62 \%$ in uncemented and $12.5 \%$ in hybrid hips.

Average age was 68.53 years, 153 males (48.88\%), 160 females (51.11\%). Average blood loss were measured, In cemented hips $357 \mathrm{ml}$, uncemented hips $293 \mathrm{ml}$.

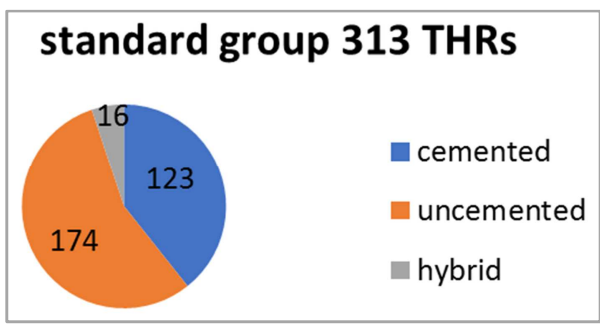

Figure 4. Standard group stratification regarding to fixation type.

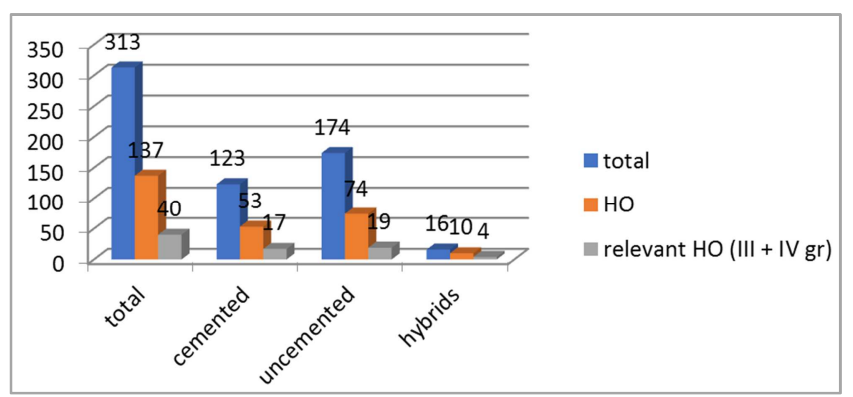

Figure 5. Quantity of particular hips, ossifications and clinically relevant cases in standard group.

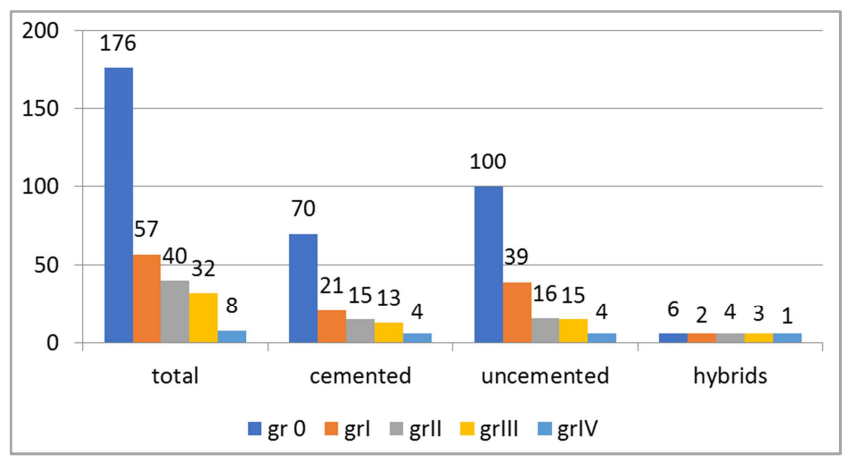

Figure 6. Amounts of particular Brooker grades of ossifications in standard group.

In alternative electromyotomy group there were 369 hips with 86 HO $(23.30 \%)$, clinically relevant $\mathrm{HO}$ cases developed in $5.69 \%, 21$ patients. The particular Brooker grades were: I. 45 , II. 20, III. 15 and IV. 6 patients, $41.60 \%$, $29.19 \%$. 23.35\% and 5.8\% respectively (of total ossifications in this group). HO in particular types: 139 cemented hips with 43 HO (0: 96, I: 19, II: 11, III: 10, IV: 3), uncemented 228 with 42 HO (0: 186, I: 26, II: 8, III: 5, IV: 3 ) and hybrid 
2 with $1 \mathrm{HO}$ (gr II). Average age was 70.56y, males 171, females 198. Average blood loss were measured, $301 \mathrm{ml}$ in cemented and $213 \mathrm{ml}$ in uncemented types.

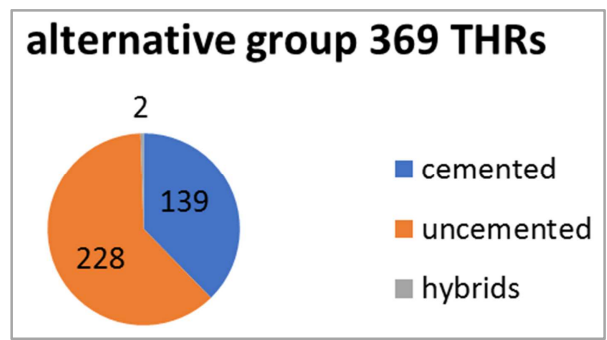

Figure 7. Testing group stratification regarding to fixation type.

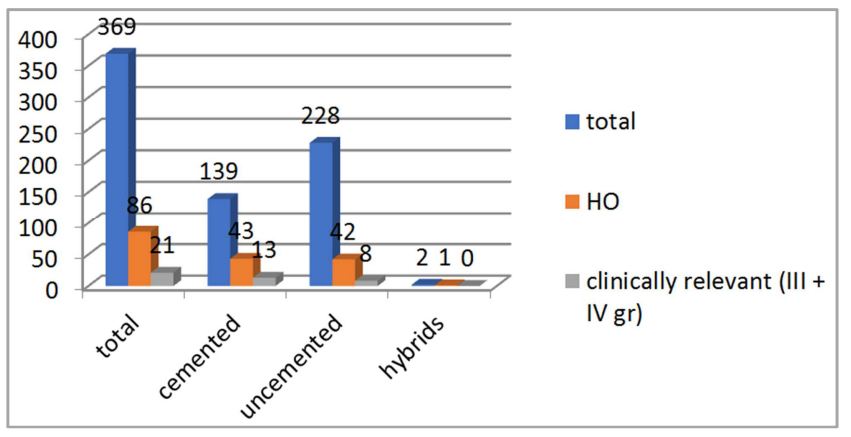

Figure 8. Quantity of particular hips, ossifications and clinically relevant cases in testing group.

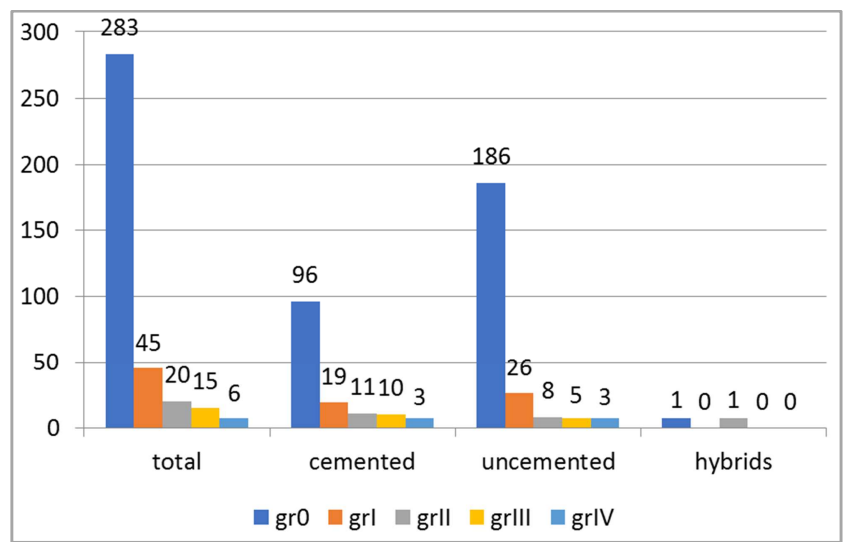

Figure 9. Amounts of particular Brooker grades of ossifications in testing group.

Statistic values of $\mathrm{HO}$ occurence between these groups favourising the electromyotomy group were significant, as such comparing the particular Brooker grades distribution and prosthesis (cemented, uncemented) type as follows. The statistical assessment of the frequency of ossification between both groups by Fisher exact test statistic value is 0.0001 is significant at $p<0.05$. Groups are compared in particular grades distribution reduction (total, cemented, uncemented, hybrids) in Wilcoxon Signed-Rank test calculated both $W$-value and $z$-value. Results $W$-value: 0 , mean difference: 2 , sum of ranks: 78 . The $Z$ - value is -3.0594 . The two-tailed $Z$-value is -3.0594 , the $p$-value is 0.00222 . The result is significant at $\mathrm{p}<0.05$. The $W$-value is 0 , critical value tor $\mathrm{W}$ at $\mathrm{N} 12(\mathrm{p}<0.05)$ is 13 . The result is significant at $p<0.05$. That represents statisticaly significant drop in counts of ossifications in electromyotomy group in particular THRs fixation tytpes. Comparing the clinically relevant (Brooker grades III and IV) HO in both groups the Fisher Exact test statistic value is 0.0046 and is significant at $p<$ 0.05 . This means the electromyotomy technique doesn't stop the development of clinically relevant grades, rather diminishes the overall number of these ossifications. Comparing the particular fixation strategies, in cemented types the ossification development in Fisher exact test the statistic value is 0.1897 and is not significant. In uncemented types the value is 0.0001 and is significant at $p<0.05$. That means the drop in HO numbers is remarkable in uncemented THRs. The decrease of blood loss in the cemented and also uncemented implants is significant, the Fisher exact test statistic value is 0.0485 , at $\mathrm{p}<0.05$, and less than 0.0001 respectivelly.

A statistically significant difference in the outcomes of electromyotomy group was found and thus our zero hypotnesis was refuted (in overall numbers and also in clinically relevant grades).

\section{Discussion}

Anterolateral approach in the implantation of total hip replacement is risky for subsequent occurrence ofheterotopic ossifications [10, 22]. However, it has undeniable advantages for placing and controlling the position of components and has a low luxation rate [7]. In addition, when implanting a straight femoral stem, it is necessary to expose the trochanteric region to achieve the entrance to the femoral canal. This is the main disadvantage of these stems comparing the so- called banana-shaped stems or conservative stems. This surgical step may be risky in terms of a potential injury to the vessels of the trochanteric anastomosis. The trochanteric osteotomy for access to the marrow cavity of the femur could preserve the vascular supply of surrounding soft tissues and reduces the incidence of heterotopic ossifications [22]. This is not routinely used due to the healing issues of the osteotomy in our departement.

The overall rate of ossifications in our group of 682 patients was $32,69 \%, 223$ hips. These numbers are comparable to the literature $[8,13,23]$. The incidence of clinically significant (Brooker grades III and IV) ossifications was $8.94 \%, 61$ hips in our cohort. This ratio variates between $0.5 \%$ and $12.3 \%$ in other studies [8]. There are several methods to influence the frequency of heterotopic ossifications before surgery. Selection of so-called risk patient for administration of secondary prophylaxis (radiotherapy and/or pharmacotherapy) [25], the correct technique with soft tissue management, choice of the approach, type of prosthesis, hemostasis and blood management, administration of tranexamic acid are described in the literature [4].

There are several theories of the origin of progenitors producing heterotopic ossifications, bone marrow stem cells [21] of the interstice cell between muscle fibers [28], fully 
differentiated endothelial cells [16] are examined, which then pass through transformand intothe mesenchymal progenitor of osteoblasts [15], cells circulating in circulation [26]. The osteoblasts producing heterotopic ossification originates in a pluripotent stem cell of neurogeneous origin [13]. Thus, the first steps of the process of bone formation probably takes place at the level of the sensory nerve and its blood vessels. This consideration is confirmed by other authors, who identified the immediate expression of pain mediators, substance P and CGRP when BMP-2 is introduced into the muscle [23]. This led to the initiation of an inflammatory reaction resulting in mastocyte degranulation and remodeling of the sensory nerve epineurium in the muscle near the injection site. The electromyotomy technique can slow down these processes by creating a local thermal necrosis of tissues and establishing subsequent reparation processes and shifts in cytokine pathways by its own thermal impact. It can also affect balance between regeneration and pathological ossification in the sequence of inflammation, tissue damage, adipogenesis, hypoxia, vasculogenesis, and finally ossification in muscle tissue [5]. Electrotoms with a power of up to $50 \mathrm{~W}$ are used in ophthalmology and dentistry, devices with higher performance in abdominal surgery and traumatolog [9]. Triggered changes in tissues depend on the voltage and intensity of the current, tissue resistance, frequency, anatomical localization of the lesion and its extent, length of application, shape of the active electrode, type of current. Clinical data from joint replacement registries show that muscle damage is a risk factor for the development of heterotopic ossification [3]. To repair the damaged muscle, $\mathrm{m}$-progenitors are activated, which in certain circumstances carry osteogenetic properties.

Influencing the muscle bleeding by electromyotomy technique with thermal separation of muscle tissue with simultaneous coagulation of microscopic muscle vessels, macroscopic vessels of trochanteric anastomosis and necrotising of nerve endings within the muscle in the incision line are potential pathogenetic pathways in our results of affecting the frequency of heterotopic ossifications. We confirm the reduction of ossification rates from $43.76 \%$ to $23.18 \%, 9.58 \%$ to $5.79 \%$ respectively for clinically significant grades (III et IV). The technique of achieving the primary stability of the prosthesis is chosen by the surgeon with the aim of immediate well fixed implant [2]. It depends on many factors: bone quality, patient age, prosthetic design and others [12]. Cemented implants are associated with a higher incidence of heterotopic ossifications [28, 30]. The suspicious surgical step for predominance in cemented stems is raspling or predrilling during the femoral canal preparation [19]. Cells with bone growth potential are spread from femoral bone marrow to surroundig soft tissues as a potential ossification nests. Uncemented implants relies on the impaction of the bone during femoral raspling, so the amount of the potential particules is much lesser. Also in other study [6] a cemented implant is associated with an increased percentage of heterotopic ossifications. We confirmed the lower ossification rate in uncemented vs. cemented replacements, $37 \%$ vs $30.4 \%$. After administration of surgical technique modification with electromyotomy the numbers break up widely, $43 \%$ vs $30.9 \%$ in cemented and $42.5 \%$ vs. $18.4 \%$ in uncemented implants. Uncemented implants are associated with a lower incidence of ossification also in our study.

The effect of polyethylene particles is considered for ossification development in the literature [29]. The assessment of the effect of high molecular weight polyethylene with radiographic controls and evaluation of osteogenesis accompanying cytokine levels and signalling pathways of the TGF- $\beta$, Runx2, MMP-9 and BMP-2 group is significant, with evidence of inhibitory effect on ossification formation. Our cemented implants were coupled metal on polyethylene, and uncemented coupling were ceramic on ceramic. Data of the occurrence of ossifications in this combination are unconvincing in the literature [22, 29].

Male sex is more risky for heterotopic ossifications after implantation of total hip replacement [19]. This correlation may be related to hormonal axis, muscle equipment and physical activity level, prostate diseases with biochemical implications for the skeleton, increased blood pressure and disturbed liver function. It is commonly accepted that postclimacteric women suffer from skeletal osteoporosis and have a lesser bone density $[18,22]$. We consistently recorded a lower incidence of ossification in women in our study, $57 \%$ vs $43 \%$.

The right handed preference of our surgeons is reflected in the increased medialization of the THR rotation center on the operated non-dominant side and the increased cup inclination during surgery on the dominant side. This is concordance with observation in literature [20]. These parameters explain the reduced incidence of ossification in our file on the dominant side, $54 \%$ vs. $46 \%$.

Haemostasis issues are well known risk factor for $\mathrm{HO}$ development, mainly if large hematomas occurred [19]. One of the positive effects of electrosurgery technique is haemostasis during the cut. The lesser the blood loss, the lesser the possibility for HO formation. Our data confirmed the decrease of blood loss in both (cemented and uncemented) groups with electromyotomy administration on statisticaly significant levels. The cementation process prolonges the surgery, that's the possible reason for greater blood loss in this group. As aforementioned, the other possibility to reduce the blood loss and $\mathrm{HO}$ formation is administration of tranexamic acid i.v. before and after the surgery [4].

Meta-analysis that evaluates 6468 hip replacements with 1939 ossifications defines the risk factors with statistical significance as follows: male sex (OR 2.11), cemented implant (OR 1.48), bilateral surgery (OR 1.74), ankylosing spondylititis (OR 1.90), hip ankylosis (OR 9.85) [30]. The opposite, rheumatoid arthritis (OR 0.51) is "protection" factor. Neutral, therefore without affecting the occurrence of ossifications, factors are: age, abuse of NSAID, neck fracture, previous neck fracture, hypertrophic hip arthritis type, multiple osteophytes $(p>0.05)$. We are in concordance with these findings in our data. A number of factors are 
endogenous and therefore cannot be influenced (sex, ankylosis, m. Bechterew etc.), but they need to be included in the prophylaxis consideration when planning the perioperative course for individualised patient plan. These patients should be included in the prophylaxis pathway for reduction the risk of heterotopic ossification formation.

\section{Conclusion}

Heterotopic ossifications are very common complication after total hip replacement. In lower Brooker grades (I or II) ossifications are asymptomatic and are only secondary finding on radiographic controls. Ossifications are a main cause of pain, limitation in range of motion, deterioration in patient function and diminish the implant expectations in certain group of patients. In a case of "risk patient" it is advisable to use secondary prevention, because once the ossification is formed and matured there is no other method to halt its progression as the only possibility is ossification exstirpation during the revision surgery. Any succesful technique or modification in primary prophylaxis counts regarding reduction the possibility of revision surgery. We present cohort longitudinal study to comparable groups of patients after total hip replacement with straight femoral stems (cemented and uncemented) through the anterolateral Watson - Jones approach with electrotomy technique compared to standard „,cold blade“ technique. Modifying the standard surgery technique by introducing an electromyotomy, the incidence of heterotopic ossifications in the field of primary prevention can be reduced. A statistically significant difference in the outcomes of electromyotomy group was found and thus we adopt this particular step in our surgery technique routinely.

\section{References}

[1] Baird EO, Kang QK: Prophylaxis of heterotopic ossification an updated review. J Orthop Surg Res. 2009; 4: 12.

[2] Biz C, Pavan D, Frizziero A, Baban A, Iacobellis C. Heterotopic ossification following hip arthroplasty: a comparative radiographic study about its development with the use of three different kinds of implants. J Orthop Surg Res. 2015; Nov 14 a10: 176.

[3] Cohn RM, Schwarzkopf R, Jaffe F. Heterotopic ossification after total hip arthroplasty. Am J Orthop. 2011 (Nov); 40 (11): E232-5.

[4] Debre J, Stepan Z, Dupal J.: Tranexamic acid reduces the incidence of heterotopic ossification after elective primary total hip prosthesis. Acta Chir Orthop Traumatol Cech. 2021; 88 (1) 13: 17.

[5] Forsberg JA, Potter BK, Polfer EM, SAfford SD, Elster EA. Do inflammatory markers portend heterotopic ossification and wound failure in combat wounds? Clin Orthop Relat Res. 2014; 472 (9): 2845-2854.

[6] Firoozabadi R, O’Mara TJ, Swenson A, Agel J, Beck JD, RouttM. Risk factors for the developmentof heterotopic ossification after acetabular fracture fixation. Clin Orthop Relat Res. 2014; 472 (11): 3383-8.

[7] Healy WL, Iorio R, Clair AJ, Pellegrini VD, Della Valle CJ et al.: Complications of total hip arthroplasty: Standardized list, definitions, and stratification developed by the hip society. Clin Orthop Relat Res 2016; 474: 357-364.

[8] Higo T, Mawatari M, Shigematsu M, Hotokebuchi T. The incidence of heterotopic ossification after cementless total hip arthroplasty. J Arthroplasty 2006; 21 (6): 852-856.

[9] Hrazdira I, Mornstein V. Medical biophysics and instrumentation. 1st edition. Brno: Neptune, 2001. p396.

[10] Hürlimann M, Schiapareli FF, Rotigliano N, Testa E, Amsler $F$ et al.: Influence of surgical approach on heterotopic ossification after total hip arthroplasty - is minimal invasive better? A case control study. BMC Musculoskelet Disord. 2017 Jan; 21 a 18 (1): 27.

[11] Jaresova Ruzickova L.: Electrosurgical and low temperature procedures. Dermatol. Praxi. 2012; 6 (4): 200.

[12] Kremers HM, Lewallen EA, van Wijnen AJ, Lewallen DG. Clinical factors, Disease parameters, and Molecular Therapies Affecting Osseointegration of Orthopedic Implants. Curr Mol Biol Rep. 2016; 2 (3): 123-132.

[13] Lazard ZW, Olmsted-Davis EA, Gugala Z, Salisbury EA, Sonnet C, Davis EL, Beal E, Ubogu EE, Davis AR. Osteoblasts have neural origin in heterotopic ossification. Clin Orthop Relat Res. 2015; 473: 2790-2806.

[14] Litman GW, Rast JP, Fugmann SD. The origins of vertebrate adaptive immunity. Nat Rev Immunol. 2010; 10 (8): 543-553.

[15] Medici D., Olsen BR. The role of endothelial-mesenchymal transition in heterotopic ossification. J Bone Miner Res. 2012; 27: 1619-1622.

[16] Medici D, Shore EM, Lounev VY, Kaplan FS, Kalluri R, Olsen BR. Conversion of vascular endothelial cells into multipotent stem-like cells. Nat Med. 2010; 16: 1400-1406.

[17] Pape HC, Lehmann U, van Griensven M, Gansslen A, von Glinski S, Krettek C. Heterotopic ossifications in patients after severe blunt trauma with and without head trauma: incidence and patterns of distribution. J Orthop Trauma 2001; 15: 229-37.

[18] Pape HC, March S, Morley JR, Krettek C, Giannoudis PV. Current concepts in the development of heterotopic ossificaiotn J Bone Joint Surg Br 2004; 86-B: 783-7.

[19] Pavlou G, Salhab m, Murugesan L, Jallad S, Petsatodis G, West R, Tsiridis E. Risk factors for heterotopic ossification in primary total hip arthroplasty. Hip Int. 2012; 22: 50-55.

[20] Pennington N, Redmond A, Stewart T, Stone M. The impact of surgeon handedness in total hip replacement. Ann R Coll Surg Engl. 2014; 96 (6): 437-41.

[21] Pittenger MF, Mackay AM, Beck SC, Jaiswal RK, Douglas R, Mosca JD, Moorman MA, Simonetti DW, Craig S, Marshak DR. Multilineage potential of adult human mesenchymal stem cells. Science. 1999; 284: 143-147.

[22] Ranganathan K, Loder S, Agarwal S, Wong V, Forsberg J, Davis TA, Wang S, James AW, Levi B. Heterotopic ossification: Basic-Science Principles and Clinical Correlates. Curent Concepts Review. J Bone Joint Surg Am. 2015; 97: 1101-11. 
[23] Salisbury EA, Lazard ZW, Ubogu EE, Davis AR, OlmstedDavis EA. Transient brown adipocyte-like cells derive from peripheral nerve progenitors in response to bone morphogenetic protein 2. Stem Cells Transl Med. 2012 Dec; 1 (12): 874-85.

[24] Shore EM, Kaplan FS. Inherited human diseases of heterotopic bone formation. Nat Rev Rheumatol. 2010; 6 (9): 518-527.

[25] Sinha S, Uchibe K, Usami Y, Pacifici M, Iwamoto $M$. Effectiveness and mode of action of a combination therapy for heterotopic ossification with a retinoid agonist and an antiinflammatory agent. Bone. 2016; 90: 59-68.

[26] Suda RK, Billings PC, Egan KP, Kim JH, McCarrickWalmsley R, Glaser DL, Porter DL, Shore EM, Pignolo RJ. Circulating osteogenic precursor cells in heterotopic bone formation. Stem Cells. 2009; 27 (9): 2209-2219.
[27] Van der Heide HJ, Rijnberg WJ, Van Sorge A, Van Kampen A, Schreurs BW. Similar effects of rofecoxib and indomethacin on the incidence of heterotopic ossification after hip arthroplasty. Acta Orthop. 2007; 78: 90-94.

[28] Wosczyna MN, Biswas AA, Cogswell CA, Goldhamer DJ. Multipotent progenitors resident in the skeletal muscle interstitium exhibit robust BMP-dependent osteogenic activity and mediate heterotopic ossification. J Bone Miner Res. 2012 May; 27 (5): 1004-17.

[29] Zeng LT, Zhu FB, Wang JY, Hou Q, Yue ZS, Yan SG, Quan RF, Zhang YL. Local influence of high molecular polyethylene particles on heterotopic ossification. Exp Ther Med. 2017; 13: 2934-2938.

[30] Zhu Y, Zhang F, Chen W, Zhang Q, Liu S, Zhang Y. Incidence and risk factors for heterotopic ossification after total hip arthroplasty: a meta- analysis. Arch Orthop Trauma Surg. 2015; 135: 1307-1314. 